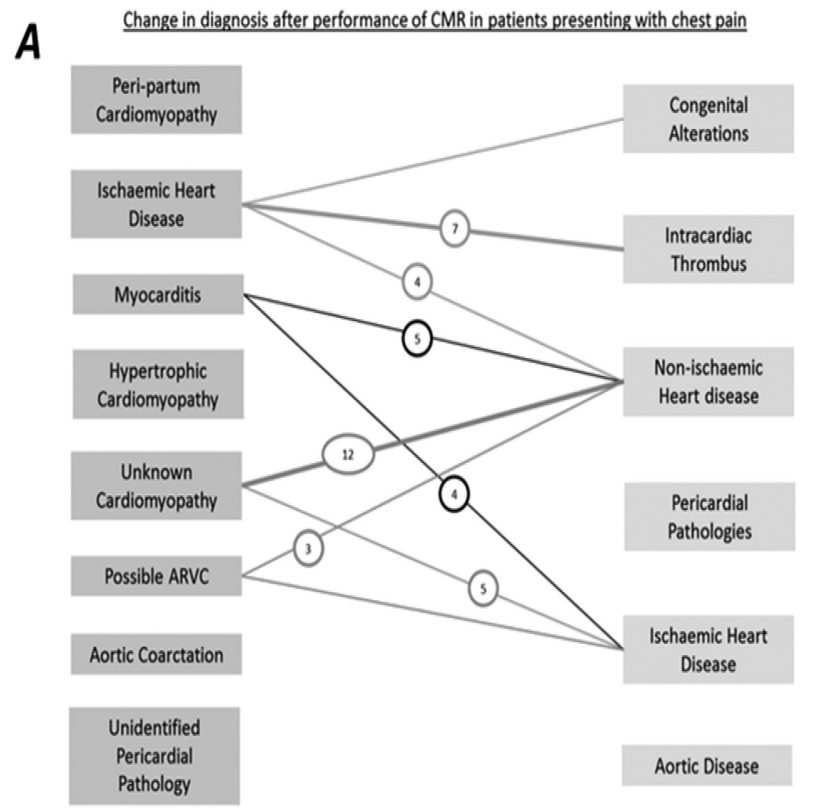

B

Change in diagnosis after performance of CMR in patients presenting with shortness of breath

C

Change in diagnosis after performance of CMR in patients presenting arrhythmias/0OHCA/Syncope

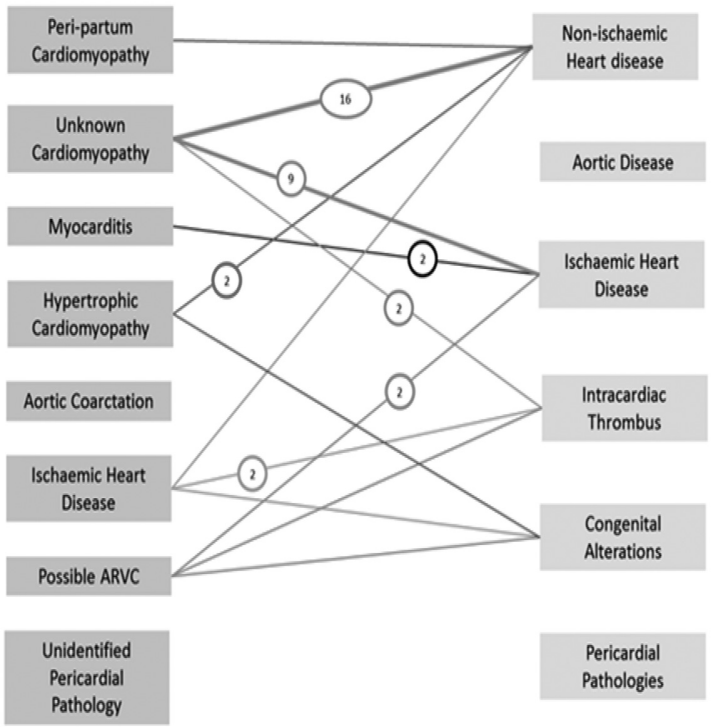

D
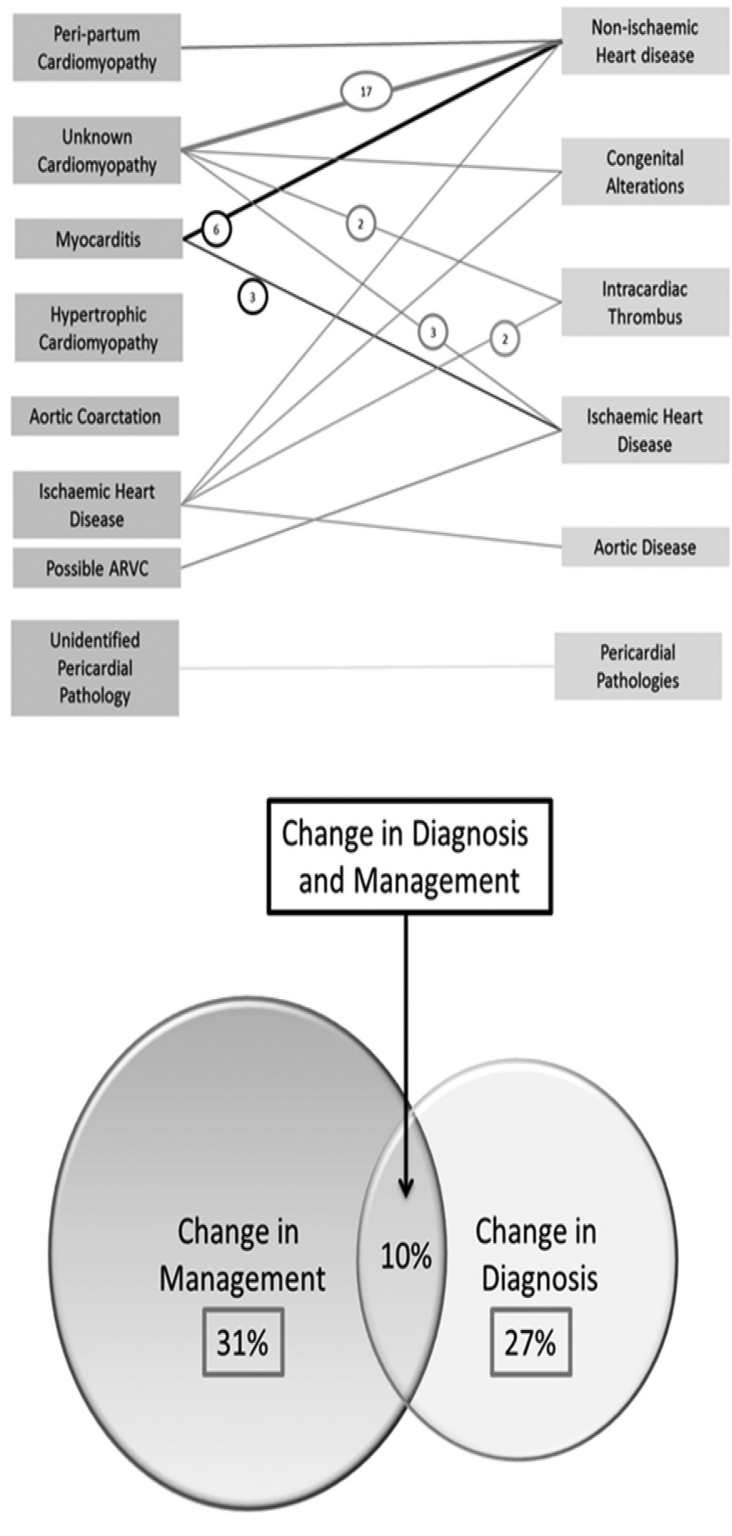

Abstract 129 Figure 1 (A) Change in diagnosis after CMR in patients with chest pain; (B) Change in diagnosis after CMR in patients with shortness of breath; (C) Change in diagnosis after CMR in patients with syncope, arrhythmias and out of hospital cardiac arrest

\section{AN INNOVATIVE AMBULATORY ECHOCARDIOGRAPHY SERVICE PROVIDES RAPID ACCESS TO TESTS, REDUCES LENGTH OF HOSPITAL STAY AND IMPROVES PATIENT CARE}

Alexandra Nowbar*, Francesca Birkinshaw, Ben Goodman, Mehdi Lesko, Gothandaraman Balaji. Northwick Park Hospital; *Presenting Author

\subsection{6/heartjnl-2016-309890.130}

Introduction Demand for urgent Echocardiography in NHS Hospitals is increasing. ${ }^{1}$ Ambulatory care unit provides rapid access to investigations and improved quality of patient care in an outpatient setting. We recently introduced Echocardiography service in Ambulatory Emergency Care Unit (AECU) at Northwick Park Hospital for low-risk cardiac patients

\begin{tabular}{lllll}
\multicolumn{6}{l}{ Abstract 129 Table 1} \\
& Sig. & Odds Ratio & $95 \%$ Conf. Interval & \\
\hline & & & Lower & Upper \\
\hline Sex & .486 & .766 & .361 & 1.622 \\
Age & .028 & 1.026 & 1.003 & 1.050 \\
Troponin & .469 & 1.000 & 1.000 & 1.000 \\
LVEF & .945 & .999 & .972 & 1.027 \\
iEDV & .827 & 1.001 & .989 & 1.014 \\
RWMA & .053 & 2.440 & .987 & 6.033 \\
LGE & .007 & 2.782 & 1.328 & 5.828 \\
Oedema & .672 & .904 & .566 & 1.444 \\
\hline Variable (s): Sex, Age, Troponin, iEDV, RWMA, LGE, Oedema &
\end{tabular}


presenting with syncope, heart failure and atrial fibrillation. The purpose of this prospective study is to assess the safety and efficacy of this service in a large district general hospital. Methods The baseline group $(\mathrm{n}=710)$ were all patients admitted to the Acute Assessment Unit (AAU) in 2013 who had an echo that appeared to be discharge-dependent (defined as an echo performed on the day of discharge). The ambulatory group $(\mathrm{n}=230)$ were consecutive patients referred to the new service for echo in the 6 months following the introduction of the service in 2015. We assessed length of stay in days and time to echo result in days in both groups. 30-day readmission, specialty referrals and estimated cost-savings were also assessed in the ambulatory group only.

Results Length of stay was lower in the ambulatory group compared to the baseline group (mean $0.57 \pm$ SD 2.12 vs $5.12 \pm 6.96, \mathrm{p}<0.00001)$. Similarly, time to echo result was lower in the ambulatory group compared to the baseline group $(0.82 \pm 2.38$ vs $2.02 \pm 4.22, \mathrm{p}=0.00002)$ (Figure $1)$. In the ambulatory group (Table 1), 25 patients (11\%) were re-admitted at 30 days. 98 patients were referred to a specialty, most commonly cardiology $(\mathrm{n}=74)$, neurology ( $\mathrm{n}$ $=7)$ and respiratory $(\mathrm{n}=5)$. Approximately 920 bed days were saved by offering echo in ambulatory care (assuming 4 days saved per patient). This amounts to an estimated $£ 253,000$ saving (assuming a cost of $£ 275$ per excess bed day) over 6 months.

Conclusion Echocardiography service in Ambulatory Emergency Care Unit reduces length of stay in hospital, provides rapid access to investigations for cardiac patients, with no significant increase in 30 day re-admission rates. The results show a significant cost savings together with improved quality of patient care.

\section{REFERENCE}

1 Macdonald MR, Hawkins NM, Balmain S, Dalzell J, McMurray JJ, Petrie MC. Transthoracic echocardiography: a survey of current practice in the UK. QJM. 2008;101(5):345-9. doi: 10.1093/qjmed/hcm135.

\section{Abstract 130 Table 1 \\ Ambutatory group demographics \\ Age (mean \pm SD) \\ $62 \pm 19$ \\ Male \\ $112(49 \%)$ \\ Sycope pothwry \\ 81 (35\%) \\ Atril fibrillation pathway \\ $36(16 \%)$ \\ Heart failure pathway \\ $30(13 \%)$ \\ Other candac pathway \\ $45(20 \%)$ \\ Non-cardiac pathway \\ $3 \mathrm{~B}(17 \%)$ \\ 30-dry readmission \\ 25 (II)}

${ }^{1}$ Shahram Ahmadvazir*, ${ }^{1}$ Kostas Zacharias, ${ }^{1}$ Benoy Shah, ${ }^{1}$ Christopher Kinsey, ${ }^{1}$ Grace Young, ${ }^{2}$ Roxy Senior. 'Department of Cardiology, Northwick Park Hospital; ${ }^{2}$ Royal Brompton Hospital* \& Northwick Park Hospital; *Presenting Author

\subsection{6/heartjn-2016-309890.131}

Background Presence of carotid artery disease has been shown to predict cardiovascular risk beyond traditional risk factors. However, the potential impact of carotid disease (CD) in patients undergoing stress echocardiography (SE) for new-onset chest pain without known coronary artery disease (CAD) is

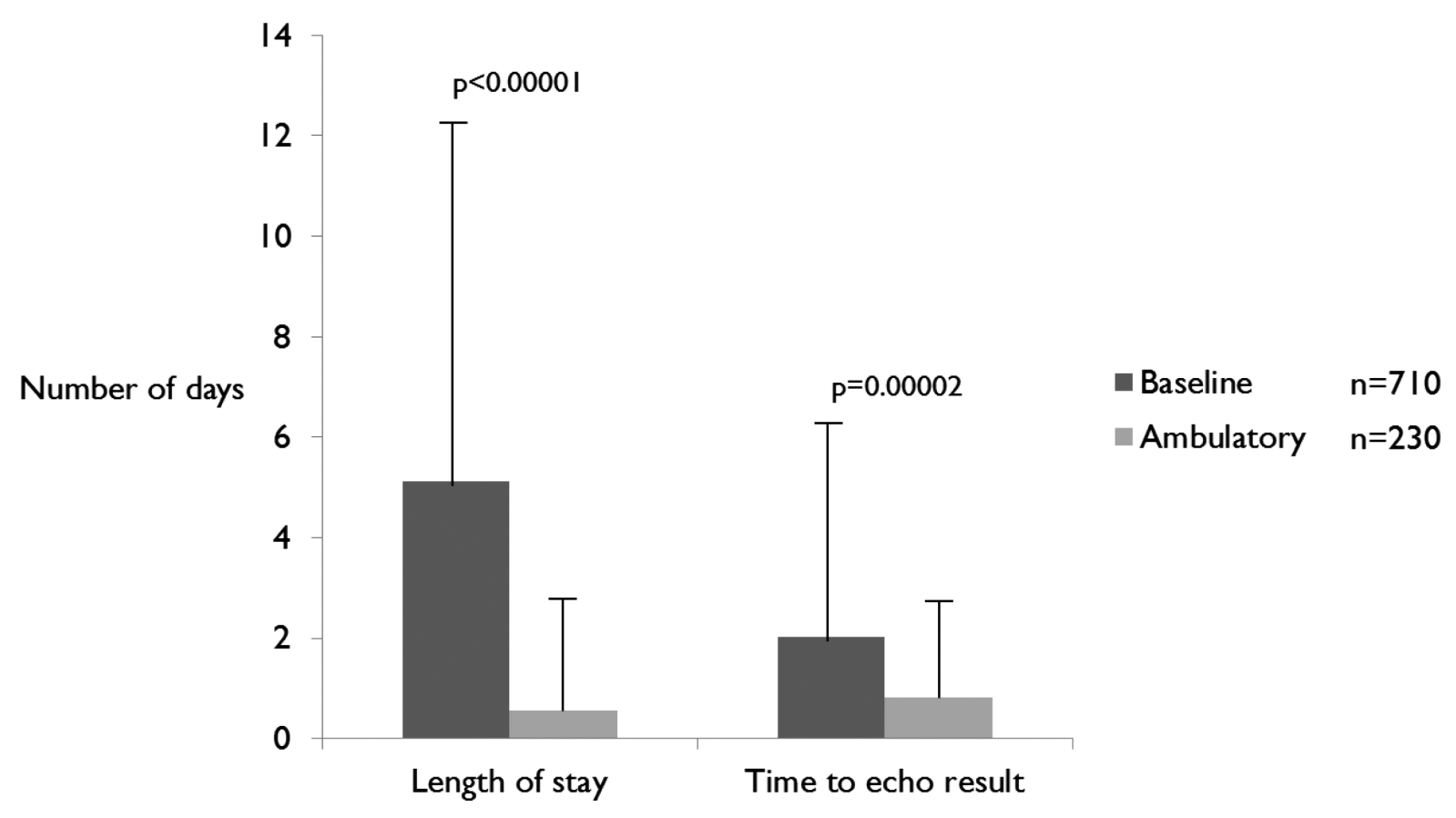

Abstract 130 Figure 1 